Civil Engineering

Volume 168 Issue CE4

A review of satellite positioning systems for civil engineering

Roberts, Tang and Brown
Proceedings of the Institution of Civil Engineers Civil Engineering 168 November 2015 Issue CE4 Pages 185-192 http://dx.doi.org/10.1680/cien.15.00013 Paper 1500013

Received 17/03/2015_Accepted 30/06/2015

Published online 18/08/2015

Keywords: Keywords: communications \& control systems/ information technology/land surveying

ICE Publishing: All rights reserved
.

\title{
A review of satellite positioning systems for civil engineering
}

1 Gethin Wyn Roberts BEng, PhD, FCInstCES, FHEA Professor of Geospatial Engineering, University of Nottingham Ningbo, China
2 Xu Tang BSc, PhD Senior Research Fellow, University of Nottingham Ningbo, China

3 Chris Brown BSC, CEng, FIMechE, CSCi, MIPEM

Reader in Applied Mechanics, Brunel University London, UK
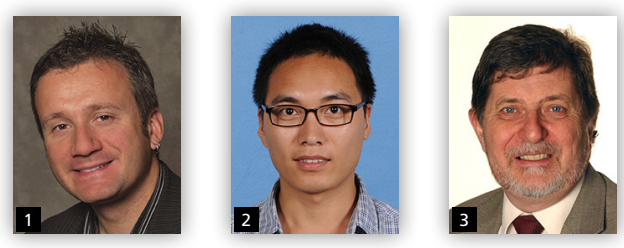

This paper informs and updates civil engineers of the status and advances of global navigation satellite systems, and how this will affect the profession in the near future. An overview of the various global and regional systems is given. Real data are used to show the potential precision of the US Global Positioning System and other global navigation satellite systems, as well as the advantages of using a multi-system approach. The results illustrate that there is a clear increase in the availability of satellites through a multisystem approach, as well as an improvement in the resulting coordinate precision.

\section{Introduction}

This paper informs and updates civil engineers on the advances in global navigation satellite-positioning systems (GNSS) technologies since the papers by Cruddace and Faye (2009) and Hancock et al. (2009), and how this will affect civil engineering surveys in the near future.

The paper introduces the variety of GNSS, and shows how a multiGNSS approach can improve the precision, reliability and increase the availability of satellites for civil engineering applications.

A study in 2003 (Parker, 2003) stated that research into the availability of the US Global Positioning System (GPS) signals for positioning in urban areas in Leeds and London found that GPS positions were only possible on $60 \%$ of the points surveyed to the required accuracies for positioning utility cables and pipes.

The previous work (Cruddace and Faye, 2009; Hancock et al., 2009) highlighted the upcoming advancements in GNSS and the use of simulation to predict scenarios with more GNSS satellites, as well as using 'pseudolites' to augment the GPS signals (Hancock et al., 2009).

Research has been carried out, illustrating the advantages of integrating GPS with other GNSS, or even a multi-GNSS solution (Roberts and Tang, 2015; Teunissen et al., 2014; Zhang et al., 2011). This paper illustrates, using real data, the potential accuracies and availability of a multi-GNSS approach compared with GPS alone.

\section{Global navigation satellite systems}

GNSS is the generic term used for all satellite navigation systems that have a global coverage (Lekkerkerk, 2014a). The most established GNSS is the American GPS, but there are currently three further GNSS either in operation or under development. These are the Russian Globalnaya Navigatsionnaya Sputnikovaya Sistema (Glonass), the European system Galileo and the Chinese BeiDou System (Cruddace and Faye, 2009; Hancock et al., 2009).

Currently there are 31 operational GPS satellites (GPSWorld, 2015), Glonass has 24 operational satellites (Dvorkin et al., 2012; Krasovskii, 2010; Nikitin, 2008), Galileo has six operational satellites (Cai et al., 2014; Lekkerkerk, 2014b; Mastracci and Fromm, 2004) and BeiDou has 15 operational satellites (Chen et al., 2009; Yuan, 2014).

Both GPS and Glonass are now (2015) fully operational, while both Galileo and BeiDou are planned to be fully operational by 2020. All the GNSS orbits consist of mid-earth orbiting (MEO) satellites, at altitudes ranging between $19130 \mathrm{~km}$ and $23222 \mathrm{~km}$ above the Earth's surface.

In addition to MEO satellites, the BeiDou satellite constellation includes a number of geostationary earth orbit (GEO) and inclined geosynchronous orbits (IGSO) satellites at an altitude of $35786 \mathrm{~km}$ above the Earth's surface (CSNO, 2013).

Table 1 illustrates the current and optimal number of operational satellites in orbit. This is a snapshot, as satellites will be launched and ones in orbit will gradually come to the end of their lives.

In addition to GNSS, there are regional navigation satellite systems (RNSS) in various parts of the world, providing spacebased augmentation systems (SBAS) to GNSS. This is where countries or regions have placed additional satellites that both behave as GPS satellites, providing additional ranges from the satellites to the users, and are also being used to transmit corrections for a differential GPS (DGPS) solution within that region.

The various generations of GPS satellites have gradually evolved to improve not only the users' positional accuracies, and signal quality and strength, but also the lifespan of the satellites. 
A review of satellite positioning systems for civil engineering Roberts, Tang and Brown

\begin{tabular}{|lccc|}
\hline & $\begin{array}{c}\text { Current } \\
\text { operational } \\
\text { satellites }\end{array}$ & $\begin{array}{c}\text { Spare satellites } \\
\text { in orbit (not } \\
\text { broadcasting } \\
\text { signals) }\end{array}$ & $\begin{array}{c}\text { Optimal satellite } \\
\text { constellation }\end{array}$ \\
\hline GPS & 31 MEO & 4 MEO & 24 MEO \\
\hline Glonass & 26 MEO & & 24 MEO \\
\hline BeiDou & 4 MEO, 5 IGSO, 6 GEO & 27 MEO, 5 IGSO, 5 GEO \\
\hline Galileo & 6 MEO & 30 MEO \\
\hline
\end{tabular}

Table 1. Current and optimal numbers of satellites in the GNSS orbits - these include MEO, IGSO, and GEO orbits (information sourced from GPSWorld (2015))

The expected lifespan of the satellites has increased over the generations from $7 \cdot 5$ years for the initial GPS operational block II and IIA satellites, to 12 years for the current block IIF satellites (Figure 1), and 15 years for the next generation is anticipated.
The reality is that the satellites have been lasting much longer. For example, on 6 January 2015, the final GPS block II satellite was taken out of service, after being in operation for over 22 years (Navcen, 2015).

The system itself has also been modernised through the introduction of more ground monitoring stations. These give the capability to improve the accuracy of the satellites' coordinates, and hence the users' coordinates, as well as reliability through being able constantly to monitor the satellites' characteristics from an increased number of ground control points.

The more recent and future generations of satellites transmit additional frequencies as well as new signals. This will improve the potential applications of such systems (Hofmann-Wellenhof et al., 2003, 2008).

GNSS signals can be processed and analysed in many ways, each resulting in different levels of accuracy and precision (Cruddace and Faye, 2009; Hancock et al., 2009; Hofmann-Wellenhof et al., 2003, 2008).

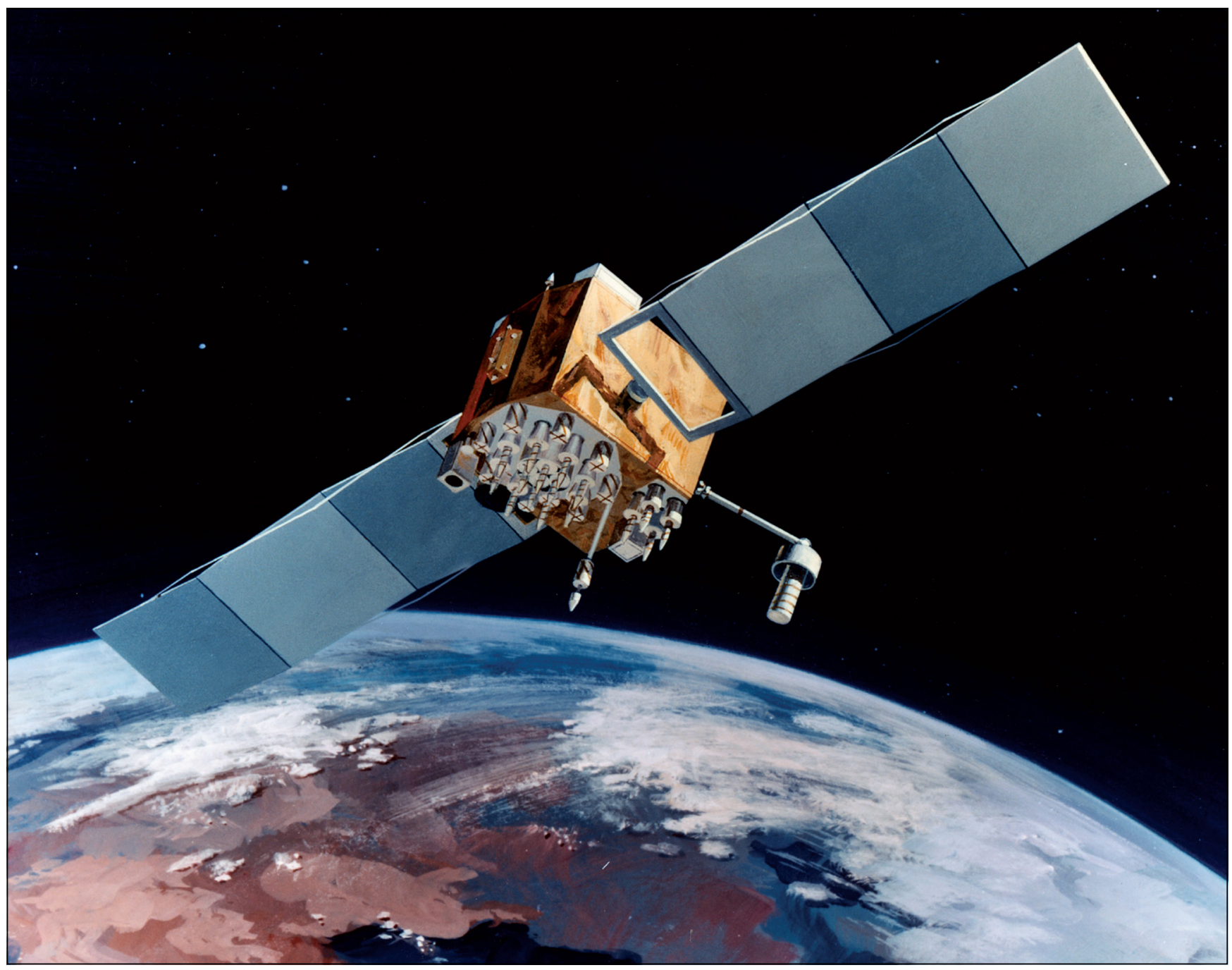

Figure 1. The nine operational GPS block IIF satellites are expected to last 12 years 
The GNSS receivers used for civil engineering surveying applications use a part of the satellite signal called the carrier phase. The resolution of the carrier phase signal is of the order of better than $0.5 \mathrm{~mm}$, and can result in coordinates with precisions from a few millimetres to a couple of centimetres depending on the type of equipment used and processing carried out.

There are a number of ways that carrier phase signal data can be processed, including static GNSS, stop-and-go kinematic GNSS, and full kinematic GNSS using what is called 'on-the-fly ambiguity resolution' (Hofmann-Wellenhof et al., 2003, 2008).

They are all relative positioning techniques, whereby the GNSS receiver, the position of which is being calculated, is located relative to a GNSS receiver located at a known coordinate, or even a network of GNSS receivers with known coordinates (HofmannWellenhof et al., 2008).

The data can be gathered and post-processed, or all the data can be brought together, typically at the unknown GNSS receiver, and processed in real time by connecting the GNSS receivers with a low-powered $0.5 \mathrm{~W}$ ultra-high frequency data link, or mobilephone-based telemetry. This real-time approach is usually only carried out for the stop-and-go, and full kinematic positioning techniques, and known as 'real-time kinematic' GPS (RTK-GPS).

Table 2 illustrates some of the main processing techniques, indicating the potential accuracies as well as their limitations and advantages.

\begin{tabular}{|c|c|c|c|}
\hline Positioning technique & $\begin{array}{l}\text { Nominal plan } \\
\text { accuracies: } m\end{array}$ & Advantages & Disadvantages \\
\hline \multicolumn{4}{|l|}{ Pseudorange positioning } \\
\hline Stand-alone positioning & $5-10$ & $\begin{array}{l}\text { Very cheap receivers, used in smart phones } \\
\text { No need for a reference GNSS receiver }\end{array}$ & $\begin{array}{l}\text { Not used for surveying, precision and accuracy not high } \\
\text { enough for most applications }\end{array}$ \\
\hline $\begin{array}{l}\text { DGNSS } \\
\text { (relative positioning to a } \\
\text { reference GNSS receiver, } \\
\text { or network of receivers) }\end{array}$ & $0 \cdot 8-3$ & $\begin{array}{l}\text { Relatively cheap compared to carrier phase equipment } \\
\text { Distance to the reference receiver can be up to } 200 \mathrm{~km}\end{array}$ & $\begin{array}{l}\text { Reference receiver required, or network of reference } \\
\text { receivers }\end{array}$ \\
\hline \multicolumn{4}{|l|}{ Carrier phase positioning } \\
\hline $\begin{array}{l}\text { Static } \\
\text { (relative positioning to a } \\
\text { reference carrier phase } \\
\text { GNSS receiver) }\end{array}$ & $0.001-0.010$ & $\begin{array}{l}\text { Very accurate and precise form of surveying } \\
\text { Multipath errors are reduced through averaging out over } \\
\text { the } 30 \text { min of data gathered } \\
\text { Mainly used to establish control points for further local } \\
\text { surveys }\end{array}$ & $\begin{array}{l}\text { At least } 30 \text { min of synchronised data required from two } \\
\text { static GNSS receivers - fast static can do this in } 10 \mathrm{~min} \\
\text { or so } \\
\text { Only one location surveyed per set-up, low productivity } \\
\text { The distance between the reference and rover receivers } \\
\text { is limited to } 10-15 \mathrm{~km} \text {, as the distance-dependent } \\
\text { errors then become de-correlated. This can be } \\
\text { increased through specialised processing techniques }\end{array}$ \\
\hline $\begin{array}{l}\text { Stop and go } \\
\text { (relative positioning to a } \\
\text { reference carrier phase } \\
\text { GNSS receiver) }\end{array}$ & $0.01-0.05$ & $\begin{array}{l}\text { Single-frequency code/carrier GNSS receiver can be used, } \\
\text { less expensive } \\
\text { Once the integer ambiguities have been resolved, a } \\
\text { position at cm accuracy is possible every } 100 \mathrm{~Hz} \text {, depending } \\
\text { on the equipment used } \\
\text { Possible to obtain a real-time solution, whereby the } \\
\text { reference GNSS receiver's data are transmitted to the rover } \\
\text { by way of telemetry (RTK) }\end{array}$ & $\begin{array}{l}\text { Need to be stationary at the start of the survey at both } \\
\text { the reference and rover receiver, in order to resolve the } \\
\text { integer ambiguities and initialise the survey } \\
\text { Cannot be easily used on dynamic applications such as } \\
\text { bridge deflection monitoring or machine control } \\
\text { The distance between the reference and rover receivers } \\
\text { is limited to } 10-15 \mathrm{~km} \text {, as the distance-dependent } \\
\text { errors then become de-correlated }\end{array}$ \\
\hline $\begin{array}{l}\text { On the fly } \\
\text { (relative positioning to a } \\
\text { reference carrier phase } \\
\text { GNSS receiver) }\end{array}$ & $0.01-0.05$ & $\begin{array}{l}\text { Fast ambiguity resolution, typically within a few seconds, } \\
\text { and while the rover GNSS receiver is moving } \\
\text { Data output rates at up to } 100 \mathrm{~Hz} \\
\text { Can be used for dynamic applications such as machine control } \\
\text { or deflection monitoring of structures such as large bridges } \\
\text { Possible to obtain a real-time solution, whereby the } \\
\text { reference GNSS receiver's data are transmitted to the rover } \\
\text { by way of telemetry (RTK) }\end{array}$ & $\begin{array}{l}\text { High-cost dual-frequency code/carrier GNSS receivers } \\
\text { used, both at the reference station and surveyed } \\
\text { location } \\
\text { The distance between the reference and rover receivers } \\
\text { is limited to } 10-15 \mathrm{~km} \text {, as the distance-dependent } \\
\text { errors then become de-correlated. }\end{array}$ \\
\hline $\begin{array}{l}\text { NRTK } \\
\text { (relative positioning to } \\
\text { a network of reference } \\
\text { carrier phase GNSS } \\
\text { receivers) }\end{array}$ & $0.01-0.05$ & $\begin{array}{l}\text { No need for a reference GNSS receiver, as the network } \\
\text { provides the data. Typically, the reference receivers are at } \\
\text { permanent locations, therefore in good locations } \\
\text { Data output rates at up to } 100 \mathrm{~Hz} \\
\text { The distances between the reference stations are typically } \\
50-70 \mathrm{~km} \text { apart - the rover GNSS receiver is positioned } \\
\text { relative to these, as the distance-dependent errors are } \\
\text { modelled and calculated rather than differenced } \\
\text { Real-time solution } \\
\text { Can be used for dynamic applications such as machine control } \\
\text { or deflection monitoring of structures such as large bridges }\end{array}$ & $\begin{array}{l}\text { Large infrastructure of reference receivers required } \\
\text { Typically a national survey approach }\end{array}$ \\
\hline
\end{tabular}

Table 2. Nominal horizontal accuracies with the main advantages and disadvantages of the most commonly used GNSS positioning techniques - note errors are an indication, as these vary due to the signals and environment. Height errors are typically two to three times worse than plan 
Today, there are some 73 operational GNSS satellites and a further 15 or so SBAS/RNSS (GPSWorld, 2015). It is planned that Galileo will grow to a constellation of 27 operational plus three active spare satellites by 2019 , and BeiDou will grow to 35 satellites by 2020 .

The regional Japanese Quasi-Zenith Satellite System (QZSS) currently has one satellite but is planned to grow to four by 2017 . In addition to this there are six SBAS satellites in Europe in terms of the European Geostationary Navigation Overlay System (EGNOS), three USA Wide Area Augmentation System (WAAS) satellites operating over North America, seven planned Indian Regional Navigation Satellite System (IRNSS) satellites, two Japanese Multi-functional Satellite Augmentation System (MSAS) satellites and eight OmniSTAR satellites.

Furthermore there are ongoing discussions in many other parts of the world with regards planned SBAS and RNSS. This means that within the next few years, the number of operational positioning satellites will be over 30 RNSS and approximately 120 GNSS, compared to the originally planned 24 GPS satellites when it was first conceived in the 1970s.

While any future approach to positioning using a multi-GNSS satellite solution will improve and extend the capabilities of GPS alone, it is not a simple task to integrate these systems fully. This is due to the nature of the signals, which in itself is a large area of research in the GNSS community.

An increase in the number of available GNSS satellites used to process a positional solution will enhance the time required for an on-the-fly positional fix, as well as the resulting precision of the solution.

The multi-GNSS approach in built-up areas, such as city centres, should also allow positions to be achieved where they are sometimes not available through using GPS alone. However, the end solution may be skewed slightly due to having a black spot in the sky where there are no satellites seen due to building obstructions.

\section{RTK GNSS precision}

The integration of multiple GNSS has many advantages. These include an increase in the number of satellites seen at any one time, as well as the positional distribution of these satellites, which improves the precision due to a better geometrical solution.

An instantaneous snapshot of the location and number of satellites is important when using kinematic GNSS. Figure 2 illustrates a $5 \mathrm{~min}$ snapshot of the six GPS satellites available during this period, and Figure 3 the 25 GNSS satellites available during the same $5 \mathrm{~min}$ period. These data were recorded in Ningbo, China, at the University of Nottingham's campus. The GNSS satellites consist of six GPS, seven Glonass, one Galileo, six BeiDou, one Japanese QZSS SBAS satellite and a further four SBAS from India and Japan. An elevation angle cut off of $15^{\circ}$ was used, which is typical when using GNSS for civil engineering surveying.

Figure 4 illustrates the total number of GPS satellites available over a $20 \mathrm{~min}$ period. The number can be seen to fluctuate between five and four satellites. It can also be seen that the various dilution of precision (DOP) values fluctuate (Hofmann-Wellenhof et al., 2003, 2008).
The DOP values are an indication of the precision expected as a result of the location and geometry of the satellite constellation - the lower the number, the better the expected precision. These DOP values are calculated in the various components, such as the overall geometry (GDOP), position (PDOP), vertical (VDOP) and horizontal (HDOP).

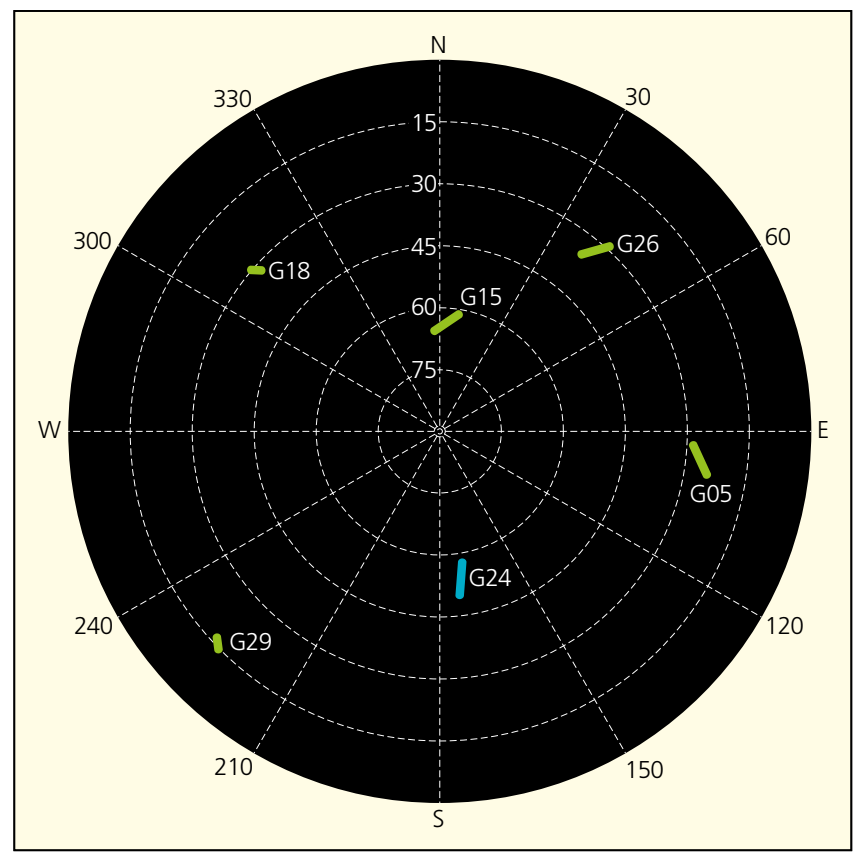

Figure 2. A 5 min sky-plot of GPS on 1 July 2014, between 21:00 and 21:05 at Ningbo, China

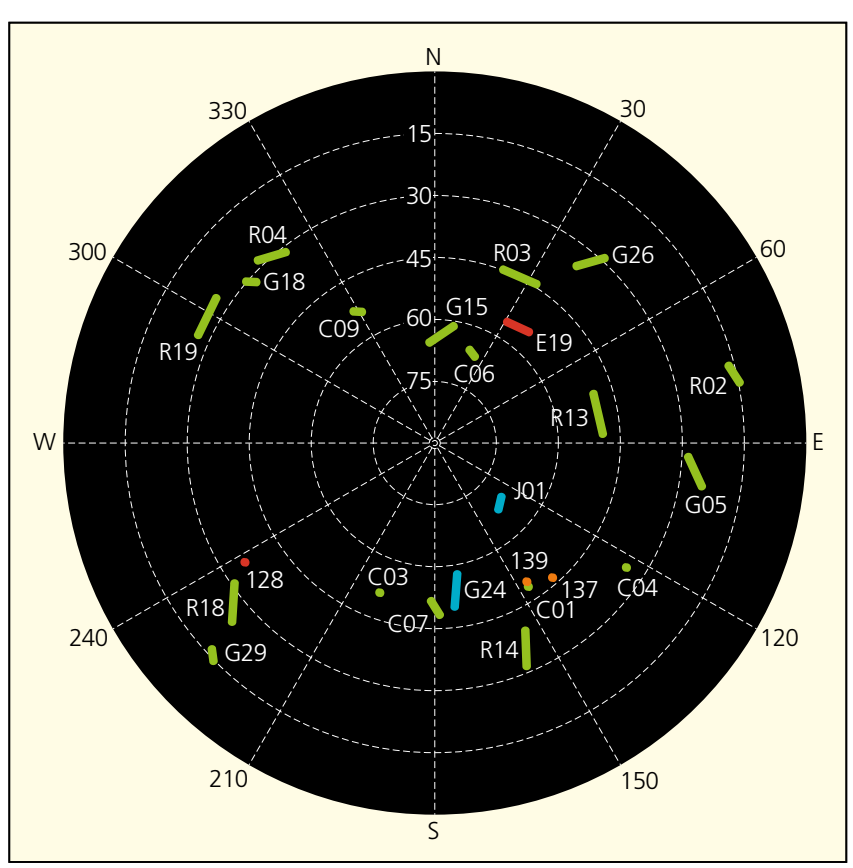

Figure 3. A 5 min sky-plot of GNSS on 1 July 2014, between 21:00 and 21:05 at Ningbo, China 
Figure 5 illustrates the number of GNSS satellites available over the same time period. Here it can be seen that the number of satellites fluctuates from 21 to 24 and, more importantly, the DOP values are constantly low. There are satellites that go in and out of view in both plots in Figures 4 and 5, but this has less of an effect on the GNSS solution compared to that obtained using GPS alone. This shows that a multi-GNSS solution is far more stable.

Figure 6 illustrates the eastings and northings results derived from a zero baseline, gathering GPS data using a Leica 1200 GPS/ Glonass receiver over a $45 \min$ period at a data capture rate of $1 \mathrm{~Hz}$. A zero baseline is where two GNSS receivers are connected to a single antenna through a signal splitting device. This results in both receivers obtaining identical signals from the GNSS antenna, including the same error components.

All external signal noise will be the same for both receivers as they receive the same data from the same antenna. The resulting apparent relative movement is due to the noise of the signals, as well as any satellite constellation geometry-induced noise. The external noise will cancel out in processing the relative coordinates (Roberts et al., 2012). Only the GPS data were used in the kinematic GPS solution presented in this paper.

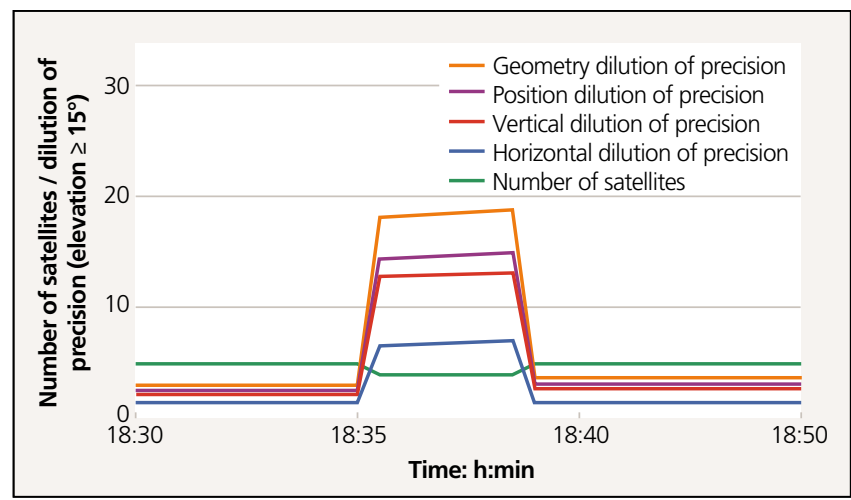

Figure 4. The total number of GPS satellites seen on 1 July 2014, between $18: 30$ and 18:45 at Ningbo, China, with a satellite elevation mask of $15^{\circ}$, in an open sky environment without any obstructions

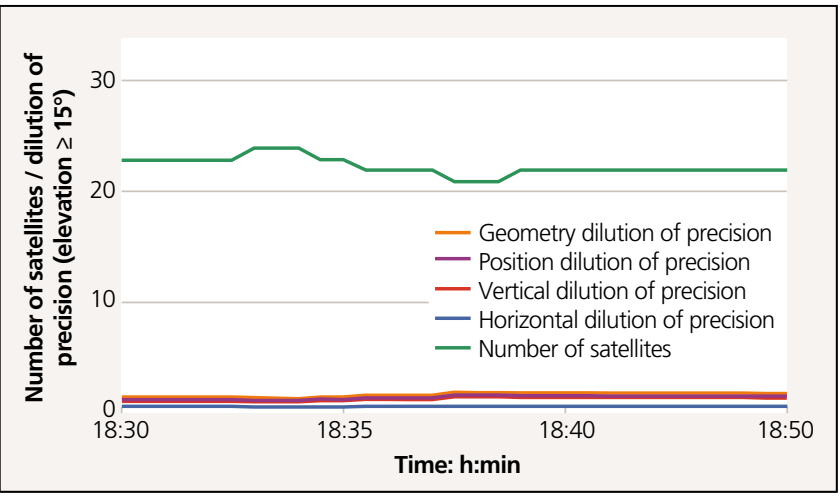

Figure 5. The total number of GNSS satellites seen on 1 July 2014, between $18: 30$ and 18:45 at Ningbo, China, with a satellite elevation mask of $15^{\circ}$, in an open sky environment without any obstructions
It can be seen in Figure 6 that it is possible to obtain coordinate precisions of the order of millimetres. The north-south error is greater than the east-west due to the satellite constellation geometry, that is, there are no satellites due north in northern latitudes such as the UK. The root mean square (RMS) values of these data are $0.7 \mathrm{~mm}$ in the north-south direction, and $0.4 \mathrm{~mm}$ in the east-west direction. The RMS of the corresponding height component is $1.2 \mathrm{~mm}$.

Figure 7 illustrates the results in the east-west component of another zero-baseline experiment, this time using two ComNav GNSS receivers (GPS, BeiDou and Glonass). Comparing the GPS and BeiDou solutions, using the BeiDou solution alone gives the least precise results with an RMS positional error of $1.22 \mathrm{~mm}$,

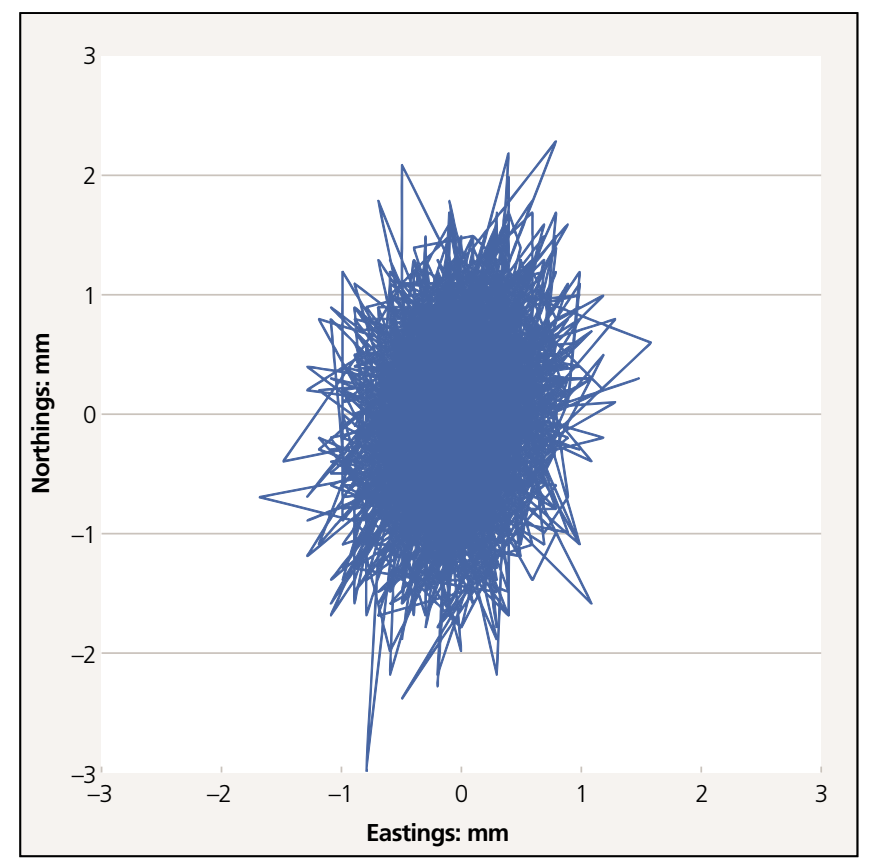

Figure 6. The results from a zero baseline kinematic GPS test, using a Leica 1200 GPS receiver data, over a 45 min period

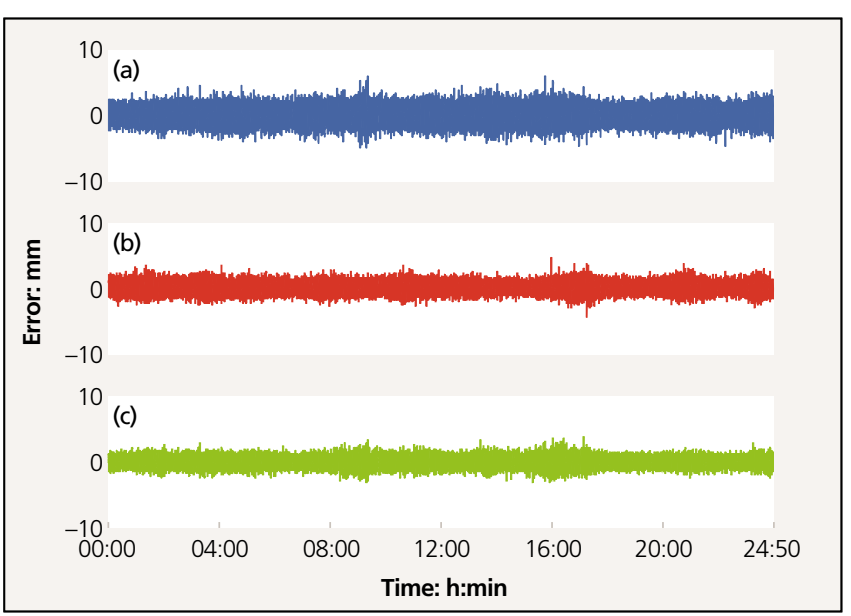

Figure 7. Position error in the east-west component for (a) BeiDouonly, (b) GPS-only and (c) integrated GPS and BeiDou solutions 
$1.03 \mathrm{~mm}$ and $3.70 \mathrm{~mm}$ in the north, east and height components respectively. This is due to the BeiDou constellation not yet being complete. The GPS solution is more precise than the BeiDou, with a positional RMS error of $0.81 \mathrm{~mm}, 0.67 \mathrm{~mm}$ and $1.94 \mathrm{~mm}$ in the north, east and height components respectively.

The combined solution is the most precise with a positional RMS error of $0.69 \mathrm{~mm}, 0.62 \mathrm{~mm}$ and $1.71 \mathrm{~mm}$ in the north, east and height components respectively. This is due to the overall satellite constellation giving a better distribution of signals. This illustrates that even though the BeiDou constellation is not yet complete, the results are still pretty decent. However, the main point is that the incomplete satellite constellation's data combined with those of GPS can improve the results of GPS alone.

\section{Some civil engineering applications of GNSS}

There are numerous applications of GPS and GNSS in civil engineering, which replicate to some extent the traditional nature of static engineering surveying, such as coordinating control points, deformation monitoring, setting out and detail surveys.
There are also dynamic applications such as deflection monitoring of large structures (Roberts and Brown, 2006; Roberts et al., 2012, 2014) positioning and controlling construction plant such as bulldozers, graders, piling rigs, mining plant, drilling rigs and excavators (Bouvet et al., 2001; Carter, 2005, 2011; Makkonen et al., 2006; Moon et al., 2010; Navon et al., 2004; Ritter et al., 2014; Seward, 2002; Seward et al., 1997).

Figure 8 shows an excavator being controlled by RTK GNSS, while Figure 9 shows a GNSS antenna located on the Severn suspension bridge cable in order to measure its deflections. Typically such GNSS results are integrated with other sensors. The excavator, for example, has its body coordinated and orientated using the two GNSS antennas. The bucket is then coordinated relative to the body, using gravity sensors or angle encoders placed on the three moving arm and bucket sections.

RTK GNSS results in real-time, three-dimensional coordinates, commonly at a rate of $20 \mathrm{~Hz}$, but potentially at rates up to $100 \mathrm{~Hz}$ with some modern receivers. This means that a dynamic system, such as a swaying bridge or moving excavator, can have its location coordinated at this rate in real time with a precision of a few millimetres. The real-time aspect of kinematic positioning is as

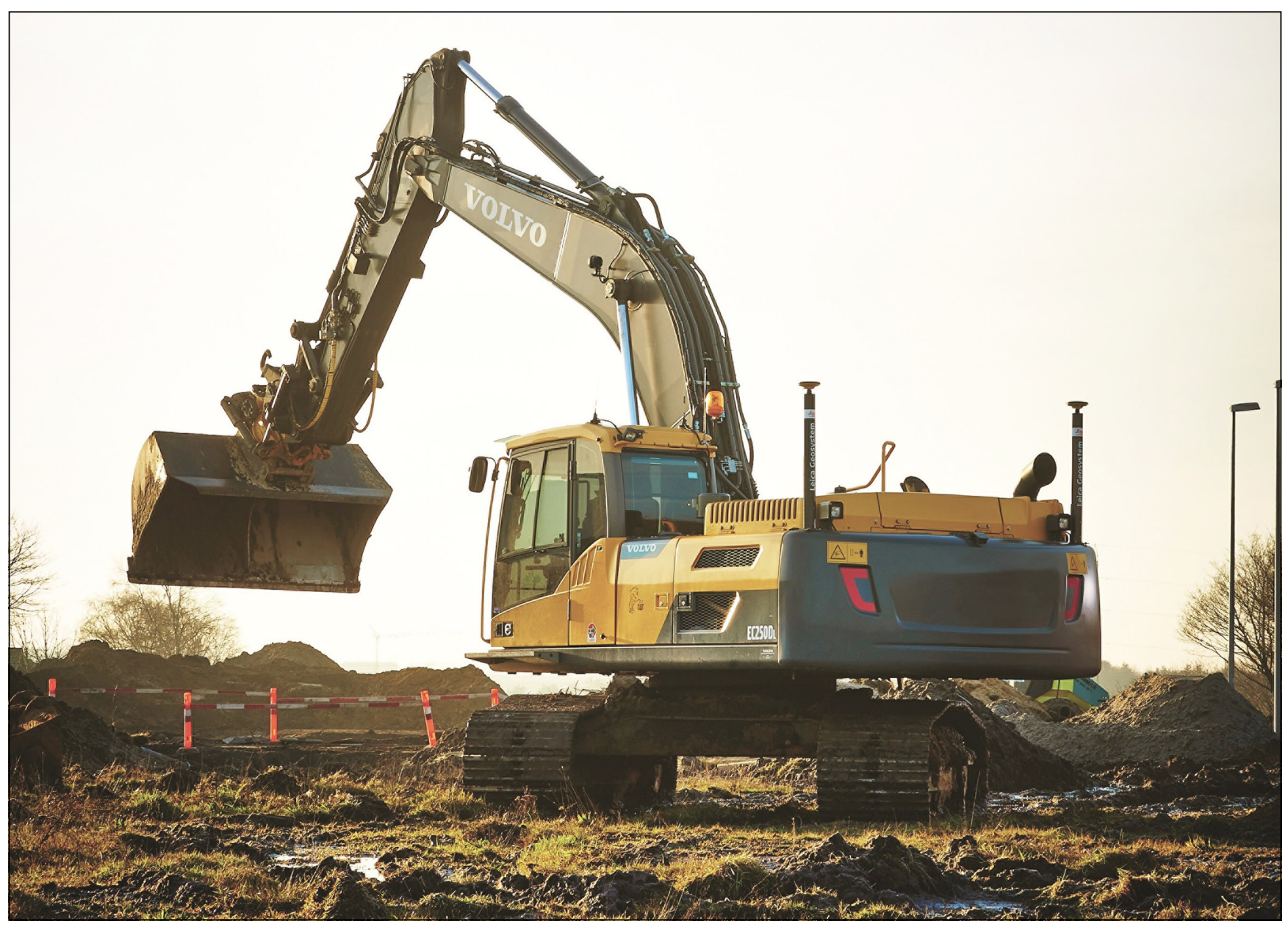

Figure 8. An excavator using RTK GNSS for control - notice the lack of setting-out sight rails and batter rails (courtesy Leica Geosystems) 


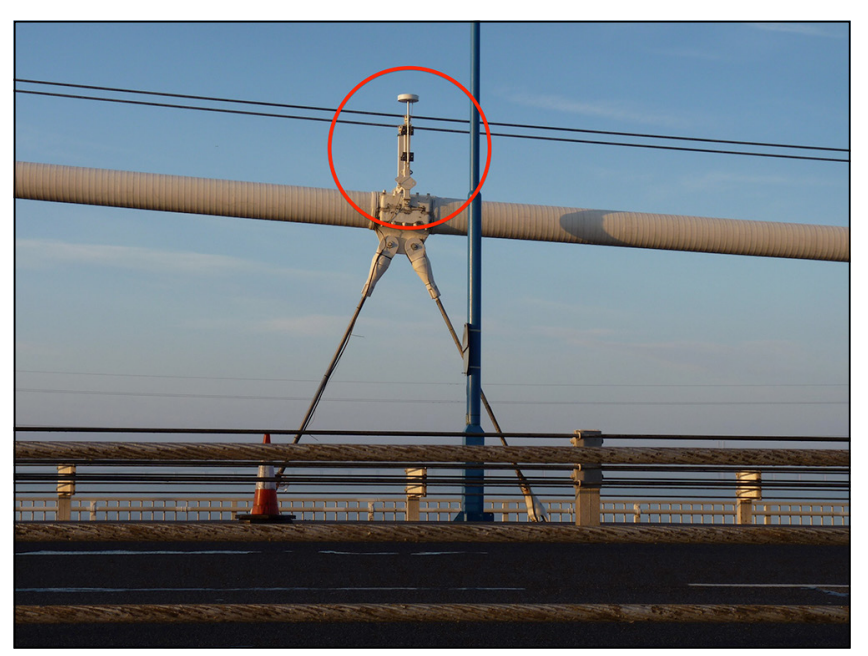

Figure 9. A GNSS antenna located on a Severn Bridge suspension cable

important to some applications as the precision itself. For example, both setting out applications and construction plant control require real-time capabilities.

Figures 10 and 11 illustrate the type of results that are possible using kinematic GPS. Figure 10 illustrates the deflection measurements of the GNSS antenna seen in Figure 9. The data were gathered at $20 \mathrm{~Hz}$, but processed at $10 \mathrm{~Hz}$ to investigate the movements of this location on the Severn Bridge.

The data gathered included dual-frequency GPS and Glonass using Leica 1200 series receivers and choke ring antennas used to reduce the multipath noise (Roberts et al., 2015). Figure 10 illustrates the typical movements, after converting the GPS coordinates into coordinates relative to the axes of the bridge. The GPS data were processed in an on-the-fly manner. Here it can be seen that the bridge deflects due to the external forces, such as traffic loading, wind loading and temperature changes. For example, the overall drop in height over the $4 \mathrm{~h}$ period in Figure 10 is $65.8 \mathrm{~mm}$. This corresponds to an increase in the steel temperature of $1.7^{\circ} \mathrm{C}$, causing the steel to elongate and hence the bridge to dip down.

There are also short-term movements seen, mainly due to the traffic loading and variation in this loading. For example, at around $13: 13$, there is a height movement from $-40 \cdot 2 \mathrm{~mm}$ to $-438 \mathrm{~mm}$, over a time of approximately $30 \mathrm{~s}$. This corresponds to a change in the traffic loading from $24030 \mathrm{~kg}$ to $170460 \mathrm{~kg}$ and then to $4530 \mathrm{~kg}$. The overall mass of traffic on the bridge at various instances were calculated using measurements from a weighin-motion system, located approximately $1 \mathrm{~km}$ off of the bridge (Roberts et al., 2015).

Figure 11 illustrates the results from carrying out a power spectral density analysis of the vertical data over a $5 \mathrm{~min}$ period. It can be seen from Figure 11 that there is a fundamental frequency of $0 \cdot 1416 \mathrm{~Hz}$ in the vertical direction from these data. These results help to illustrate the possibilities using kinematic GPS. These types of data rates and precisions could be re-produced in other civil engineering scenarios, such as construction plant control, land surveying and setting out and deformation monitoring of other types of man-made and natural structures.

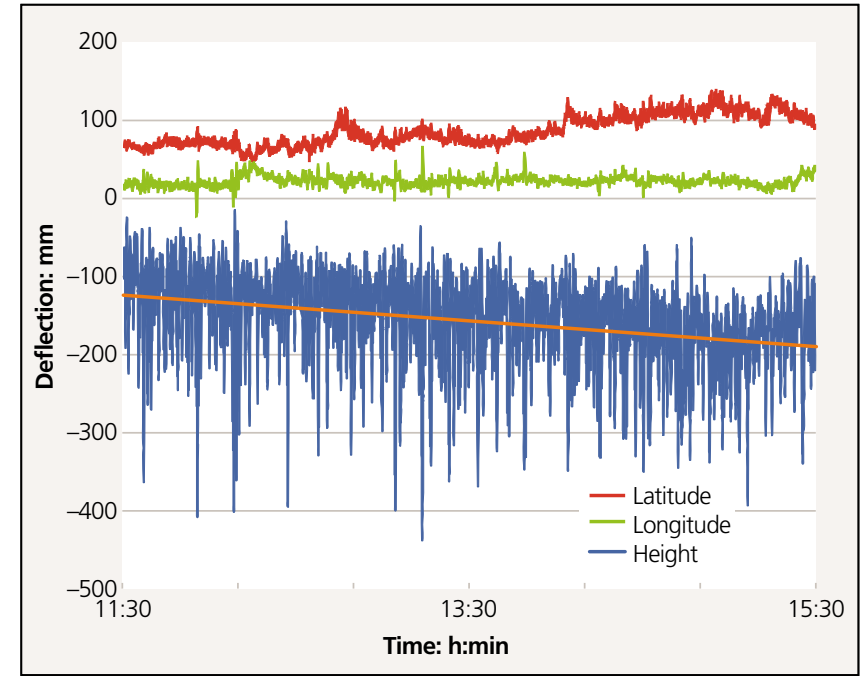

Figure 10. Lateral, longitudinal and vertical movements calculated using kinematic GPS at location C on the Severn Bridge, 18 March 2010, $11: 30$ to $15: 30$

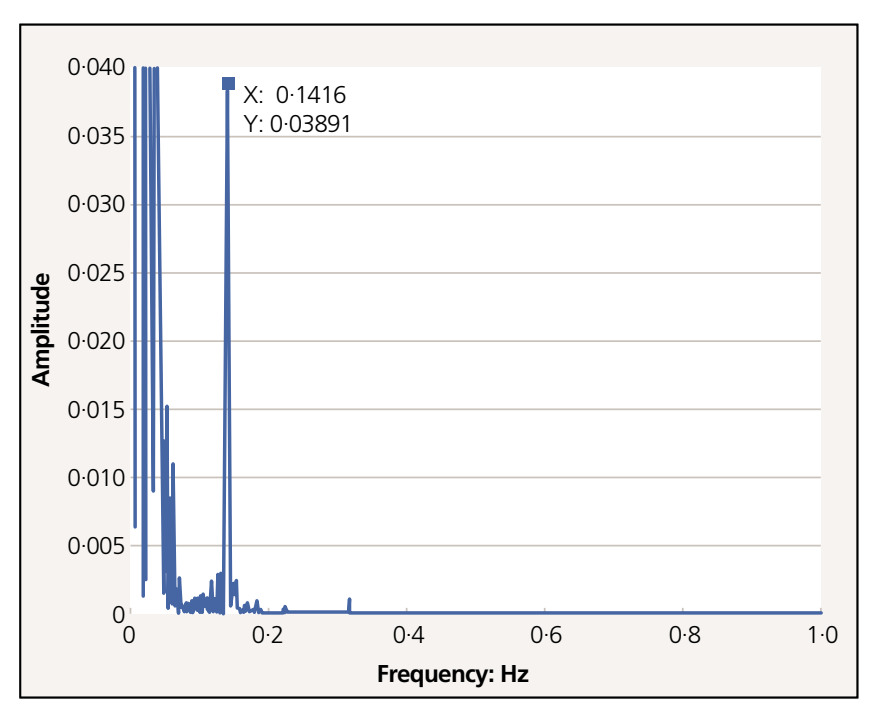

Figure 11. Power spectral density analysis of location $C$ on the Severn Bridge, illustrating a fundamental frequency of $0.1416 \mathrm{~Hz}$ in the vertical direction

\section{Final comments}

Cruddace and Faye (2009) stated, 'the future for GNSS plans to be very exciting over the next 5 years where $100+$ positioning satellites could be available to users'. The development of GNSS is ongoing, while the multi-GNSS concept has been available for 15 years or so, initially through the introduction of Glonass by Ashtech's GG24 GPS/Glonass receiver.

Today, however, there are a multitude of existing and developing GNSS and RNSS, which results in an improvement in precision and availability, as well as reliability of using such systems. The monitoring rates are determined by the quality and capability 
of the equipment to gather data. The quality of the satellites' signals, the GNSS receivers and the expected accuracies and precisions are also under improvement.

The use of multiple GNSS has a very bright future, for civil engineering in particular, and will be developed to enable surveying and positioning tasks in built-up areas such as city centres. An integrated GNSS approach will improve the accuracies and precision of the results, as well as allowing positioning in difficult environments.

Furthermore, the various GNSS are introducing new signals in the new satellites that are being launched. This means that the various GNSS will have triple frequencies, rather than dual. This will also have an advantage in being able to calculate the errors due to the upper atmosphere (ionosphere), as well as accelerating the integer ambiguity resolution. Further to this, a multiple GNSS approach will allow more rigorous self-checking to take place.

The results presented in this paper illustrate the accuracies and precisions possible using kinematic GPS and kinematic GNSS. This is also possible in real time. The paper also presents some results, illustrating that even though the BeiDou constellation is not yet complete, it is already possible to use the existing satellites, in addition to GPS, to improve the results of GPS alone.

By 2020, when BeiDou and Galileo are planned to be fully operational, the benefits of the 120+ GNSS plus extra RNSS constellation will be felt in many areas, including the many applications within the civil engineering field.

\section{References}

Bouvet D, Froumentin M and Garcia G (2001) A real-time localization system for compactors. Automation in Construction 10(4): 417-428.

Cai C, Luo X, Liu Z and Xiao Q (2014) Galileo signal and positioning performance analysis based on four IOV satellites. Journal of Navigation 67(5): 810-824.

Carter RA (2005) Mining with precision. Engineering and Mining Journal 206(4): 42-46.

Carter RA (2011) Remote possibilities. Engineering and Mining Journal 212(2): 42-48.

Chen H, Huang Y, Chiang K, Yang M and Rau R (2009) The performance comparison between GPS and BeiDou-2/Compass: a perspective from Asia. Journal of the Chinese Institute of Engineers 32(5): 679-689.

Cruddace P and Faye C (2009) A civil engineer's guide to GPS and GNSS. Proceedings of the Institution of Civil Engineers - Civil Engineering 162(4): 180-186, http://dx.doi.org/10.1680/cien.2009.162.4.180.

CSNO (China Satellite Navigation Office) (2013) BeiDou Navigation Satellite System Signal In Space Interface Control Document Open Service Signal (Version 2.0). CSNO, Beijing, China. See http://www.beidou.gov.cn/ attach/2013/12/26/20131226b8a6182fa73a4ab3a5f107f762283712.pdf (accessed 27/07/2015).

Dvorkin VV, Karutin SN and Kurshin VV (2012) Method for monitoring the glonass global navigation satellite system by means of a differential correction and monitoring system. Measurement Techniques 55(3): 284-291.

GPSWorld (2015) http://gpsworld.com/the-almanac/ (accessed 17/06/2015)

Hancock C, Roberts GW and Taha A (2009) Satellite mapping in cities: how good can it get? Proceedings of the Institution of Civil Engineers - Civil Engineering 162(3): 122-128, http://dx.doi.org/10.1680/ cien.2009.162.3.122

Hofmann-Wellenhof B, Legat K and Weisle M (2003) Navigation - Principles of Positioning and Guidance. SpringerWien, New York, NY, USA.
Hofmann-Wellenhof B, Lichtenegger $\mathrm{H}$ and Wasle E (2008) GNSS Global Navigation Satellite Systems. Springer, New York, NY, USA.

Krasovskii PA (2010) Support for uniformity of measurements in global navigation satellite systems (Glonass). Measurement Techniques 53(4): 355-360.

Lekkerkerk H (2014a) GNSS update. Geolnformatics 17(5): 30

Lekkerkerk H (2014b) How difficult can it be? GNSS update. Geolnformatics 17(7): 40.

Makkonen T, Nevala K and Heikkila R (2006) A 3D model based control of an excavator. Automation in Construction 15(5): 571-577.

Mastracci C and Fromm H (2004) European GNSS/GALILEO status. Acta Astronautica 54(11-12): 957-959.

Moon S, Yang B, Kim J and Seo J (2010) Effectiveness of remote control for a concrete surface grinding machine. Automation in Construction 19(6): 734-741.

Navcen (2015) http://www.navcen.uscg.gov/?Do=gpsShowNanu\&num=2015005 (accessed 17/07/2015).

Navon R, Goldschmidt E and Shpatnisky Y (2004) A concept proving prototype of automated earthmoving control. Automation in Construction 13(2): 225-239.

Nikitin AV (2008) Definition of the initial state of a stabilization system for frequency and time signals for a reference Glonass/GPS synchronized receiver. Measurement Techniques 51(1): 44-46.

Parker I (2003) Minimising Street Works Disruption: Buried Asset Exchange Field Trials. UK Water Industry Research, London, UK, report no. 04/WM/12/6.

Ritter R, Herzog A and Drebenstedt C (2014) Automated dozer concept aims to cut IPCC downtime. Engineering and Mining Journal 215(11): 52-55.

Roberts GW and Brown CJ (2006) Developments in the use of GPS for bridge monitoring. Proceedings of the Institution of Civil Engineers Bridge Engineering 159(3): 117-119.

Roberts GW and Tang X (2015) Accuracy analysis of GPS/BDS relative positioning using zero-baseline measurements. Journal of Global Positioning Systems, in press.

Roberts GW, Brown CJ, Meng X et al. (2012) Deflection and frequency monitoring of the Forth Road Bridge, Scotland, by GPS. Proceedings of the Institution of Civil Engineers - Bridge Engineering 165(2): 105-123.

Roberts GW, Brown CJ, Tang X, Meng X and Ogundipe O (2014) A tale of five bridges; the use of GNSS for monitoring the deflections of bridges. Journal of Applied Geodesy 8(4): 241-264.

Roberts GW, Brown CJ, Tang X and Ogundipe O (2015) Using satellites to monitor Severn Bridge structure, UK. Proceedings of the Institution of Civil Engineers - Bridge Engineering, http://dx.doi.org/10.1680/bren.14.00008.

Seward DW (2002) Automating the construction workplace: positioning and navigational factors. Construction Innovation 2(3): 167-189.

Seward DW, Scott JN, Dixon R, Findlay JD and Kinniburgh H (1997) Automation of piling rig positioning using satellite GPS. Automation in Construction 6(3): 229-240.

Teunissen PJG, Odolinski R and Odijk D (2014) Instantaneous BeiDou plus GPS RTK positioning with high cut-off elevation angles. Journal of Geodesy 88(4):335-350.

Yuan $\mathrm{H}$ (2014) Several problems on BeiDou system in coal mine measurement. Meitan Jishu / Coal Technology 33(2): 222-224 (in Chinese).

Zhang S, Zhang K, Wu S and Li B (2011) Network-based RTK positioning using integrated GPS and Glonass observations. Proceedings of the International Global Navigation Satellite Systems Society Symposium, Sydney, Australia (CD-ROM)

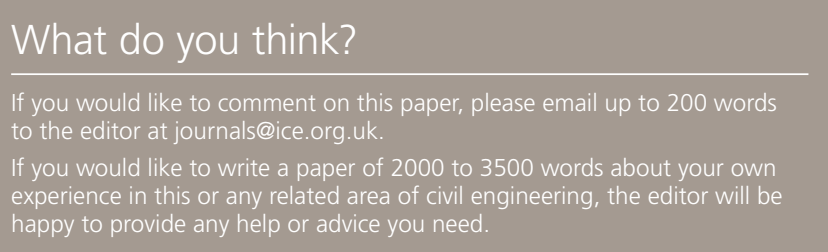

